\title{
Influence of Lightning Current Parameters and Earthing System Designs on Tower Footing Impedance of 500 kV Lines
}

\author{
Nur Alia Farina Mohamad Nasir ${ }^{1, *}$, Mohd Zainal Abidin Ab Kadir ${ }^{2}{ }^{1}$, Miszaina Osman ${ }^{1}(\mathbb{D}$, \\ Muhamad Safwan Abd Rahman ${ }^{1}$, Ungku Anisa Ungku Amirulddin 1일 , Mohd Solehin Mohd Nasir ${ }^{3}$,
} Nur Hazirah Zaini ${ }^{4}$ and Nik Hakimi Nik Ali ${ }^{5}$

1 Institute of Power Engineering (IPE), Universiti Tenaga Nasional (UNITEN), Kajang 43000, Malaysia; miszaina@uniten.edu.my (M.O.); asafwan@uniten.edu.my (M.S.A.R.); anisa@uniten.edu.my (U.A.U.A.)

2 Centre for Electromagnetic and Lightning Protection Research (CELP), Advanced Lightning, Power and Energy Research Centre (ALPER), Universiti Putra Malaysia (UPM), Serdang 43400, Malaysia; mzk@upm.edu.my

3 Faculty of Engineering, Universiti Pertahanan Nasional Malaysia, Kem Sungai Besi, Kuala Lumpur 57000, Malaysia; solehin@upnm.edu.my

4 Power, High Voltage and Energy (PHIVE) Research Group, Faculty of Engineering and Built Environment, Universiti Sains Islam Malaysia, Bandar Baru Nilai, Nilai 71800, Malaysia; nurhazirah@usim.edu.my

5 College of Engineering, Universiti Teknologi MARA, Shah Alam 40450, Malaysia; hakimiali@uitm.edu.my

* Correspondence: nuralianasir@gmail.com

check for updates

Citation: Mohamad Nasir, N.A.F.; Ab Kadir, M.Z.A.; Osman, M.; Abd Rahman, M.S.; Ungku Amirulddin, U.A.; Mohd Nasir, M.S.; Zaini, N.H.; Nik Ali, N.H. Influence of Lightning Current Parameters and Earthing System Designs on Tower Footing Impedance of $500 \mathrm{kV}$ Lines. Energies 2021, 14, 4736. https://doi.org/ $10.3390 /$ en14164736

Academic Editor: Pawel Rozga

Received: 24 June 2021

Accepted: 29 July 2021

Published: 4 August 2021

Publisher's Note: MDPI stays neutral with regard to jurisdictional claims in published maps and institutional affiliations.

Copyright: (c) 2021 by the authors. Licensee MDPI, Basel, Switzerland. This article is an open access article distributed under the terms and conditions of the Creative Commons Attribution (CC BY) license (https:/ / creativecommons.org/licenses/by/ $4.0 /)$.
Abstract: This paper presents an optimum earthing system design for improving the lightning performance of a $500 \mathrm{kV}$ transmission line for its sustainable operation. The study includes an interpretation of the soil profile and compares the results between default and new earthing arrangements for improving tower footing resistance and tower footing impedance. An evaluation of the tower footing resistance (TFR) and impedance (Ri) before and after earthing improvement was carried out. Moreover, the effects of TFR and Ri, also known as low and high-frequency earthing, respectively, based on a specification of TFR and soil resistivity (SR) ranges at various sites were also considered. The analysis was carried out using the SESCAD tool of Current Distribution Electromagnetic Field Grounding and Soil Structure Analysis software (CDEGS) and PSCAD/EMTDC software for low and high frequency earthing, respectively. From the analysis, the results showed that the new earthing arrangement reduced the TFR by $74.11 \%$ for Tower T40, 75.71\% for Tower T41 and $80.83 \%$ for Tower T42. For Ri, the results also demonstrated that the values were significantly decreased below the TFR during a high frequency operation due to the soil ionisation phenomenon that took place during the lightning. All these improvements are now being investigated and studied in all $500 \mathrm{kV}$ networks in Malaysia, where lightning is considered as a major threat in relation to power outages.

Keywords: transmission line (TL); lightning; earthing design; sol ionization; tower footing resistance (TFR); tower footing impedance (TFI); CDEGS; PSCAD

\section{Introduction}

Minimizing the earthing impedance is the correct alternative to refinements of the TL performance caused by the back flashover (BFO) phenomena. The BFO occurs when the potential exceeds the insulation strength along the string of an insulator. A high lightning current will be produced by a direct lightning strike to the tower structure and will flow along the tower into the earth. Consequently, the impulse potential will be highly detrimental and will subsequently affect the tower and the earthing device efficiency [1-6]. The system failure due to BFO is measured as a back-flashover rate (BFR) that is typically related to high tower footing impedance and soil resistivity. The tower footing impedance associated with soil resistivity is known to have a significant effect on transmission system failure [7-9]. Usually, the value of the impedance parameter must be less than the limit of the tower impedance set by the requirement of the power utility industry. In Peninsular 
Malaysia, the national grid known as Tenaga Nasional Berhad (TNB) has fixed the tower footing resistance (TFR) to be less than or equal to $5 \mathrm{ohm}(\Omega)$ for $500 \mathrm{kV}$ lines [10], although in many countries, a TFR of around $10 \Omega$ to $15 \Omega$ is considered to be as effective [11]. An earthing resistance of $10 \Omega$ is often needed in extra-high voltage (EHV) lines. Table 1 lists some tower footing resistance or impedance values that have been established by other countries.

Table 1. Earthing resistance established by other countries.

\begin{tabular}{ccccc}
\hline Country & Soil Resistivity, $\boldsymbol{\Omega} \cdot \mathbf{m}$ & TFR, $\boldsymbol{\Omega}$ & Reference & Remarks \\
\hline Peru & - & 25 & {$[12]$} & For all line ratings \\
\hline Columbia & - & 20 & {$[12]$} & For all line ratings \\
\hline Spain & - & 10 & {$[12]$} & For all line ratings \\
\hline & $\leq 100$ & 10 & & \\
China & 100 to 500 & 15 & & Measured in summer \\
& 500 to 1000 & 20 & {$[11]$} & without connecting to \\
& 1000 to 2000 & 25 & & the tower. \\
UK & $>2000$ & 30 & & For all line ratings \\
\hline Japan & - & 10 & {$[13]$} & For all line ratings \\
\hline
\end{tabular}

Therefore, to improve the efficiency of a $\mathrm{TL}$, an effective earthing design is required and this is one of the best solutions to this problem. When developing a TL, tower footing resistance is one of the important parameters to be considered. The outcome of the improvement in the TFR depends on many factors, including the earth structure and soil resistivity, among others [15-19]. The arrangement of the earthing design usually has a relationship with the form of the configuration or tower footing. At present, round steel and profiled bar earth electrodes are buried at the base of each footing before the concrete foundation is laid. Moreover, the earth electrodes and tower footing are buried together during installation. In China, the TFR was usually assigned based on the soil resistivity (SR) value, as depicted in Table 1 . For an SR exceeding $100 \Omega \mathrm{m}$, an additional earth electrode should be added i.e., a rectangular or square horizontal electrode. However, if the soil resistivity is over $4000 \Omega \mathrm{m}$, the use of a horizontal electrode along the tower and connecting an earth electrode to each tower was found to be more effective and was recommended [11,20-22].

The operation of a transmission system is greatly influenced by the earthing mechanism. The transmission line (TL) earthing system design has a major effect on the number of outages caused by lightning strikes. In particular, the response of the earthing system subjected to lightning is very different from the low frequency steady-state. This is caused by the occurrence of the soil ionisation phenomenon during lightning current discharge [23-25]. It has been recognised for many years that the soil will act non-linearly when it is subjected to a high current discharge. As a result, the voltage gradient in the soil will be generated following the equation:

$$
E=J \rho_{o}
$$

where $\rho_{o}$ is the soil resistivity and $J$ is the current density at the point considered. From there on, this would increase the electric field as the transient current is raised. In consequence, there will be a breakdown whenever the value of $E$ exceeds the critical value (ionisation gradient, Eo). Due to that, the conductor will be affected by this complication and breakdown will begin at the electrode surface whenever the current density is highest and it will continue to depart to the region at which the electric field decreases below the critical value. Subsequently, tracking along the irregular surface of the soil would be produced due to arcing appearing and this tracking would enlarge as the current density 
increases. The soil resistivity will drop simultaneously as the electric field rises. When the current density continues to increase, a small hole (puncture) in the soil will appear through the tracking and an arc would be generated as the soil resistivity at that time would be very low. Figure 1 represents the structure of the breakdown region in soil when the impulse current has passed as an arc and a spark in a non-linear region. This region would be called a soil ionisation region $[11,26]$. Whenever an earthing electrode is injected with a lightning impulse current, the soil adjacent to the earth electrode is ionised [27,28]. Due to that, the resistivity of the ionized soil drops to a low value and the TFR would be reduced automatically [29].

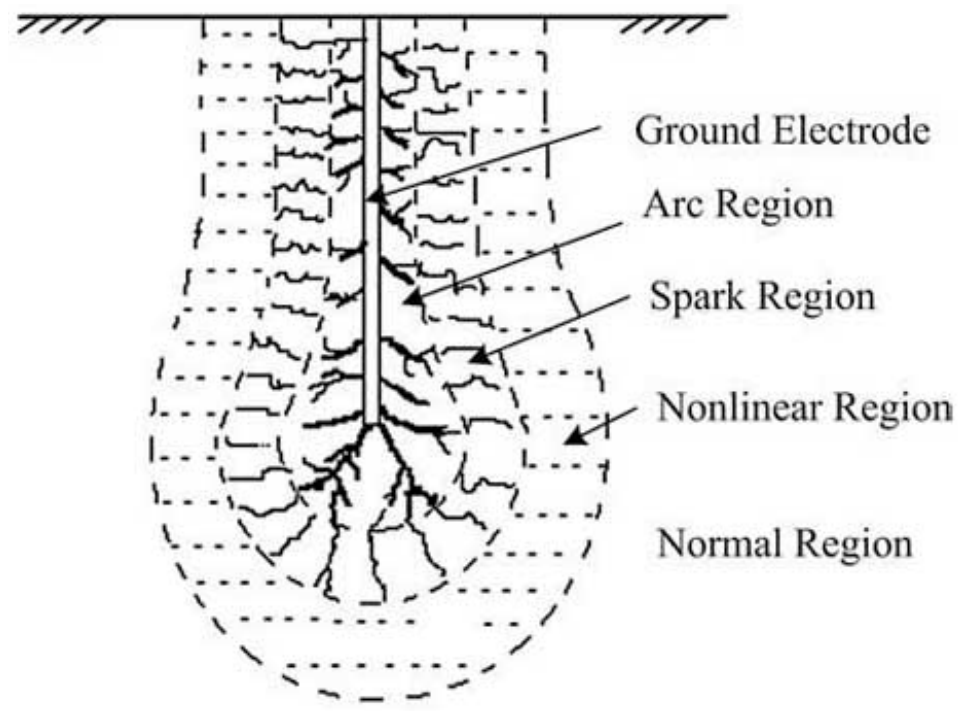

Figure 1. Breakdown region in soil near an earthing electrode [11].

A review of prior studies shows that the focus has been on earthing behaviour in uniform soil, the soil top layer depth, algorithms and the reflection factors [22,30-33]. Several studies have been based on various assumptions and physical techniques, resulting in the development of numerous equations over the last few years. Up to the authors' knowledge, despite the fact that numerous researchers have proposed solutions to these problems, there are not many analyses available based on the actual design and implementation at $500 \mathrm{kV}$ towers, which are significantly different in terms of topography, types of soil, earthing arrangements including the number of electrodes and how the impact of earthing design varies in different soil conditions on earthing system behaviour during a high current. In general there are numerous guidelines and technical materials on lightning performance studies available for both transmission [34-38] and distribution lines [39-41]. In fact, the issues of tower earthing systems and their effect on the line's lightning performance i.e., low frequency versus high frequency responses, soil ionisation and the frequency dependence of soil parameters, were among the points of discussion in the newly published CIGRE TB 839 [42], that require more studies based on real measurements and data to be carried out.

Therefore, this paper aims to evaluate the tower footing resistance before and after improving the earthing arrangement. An investigation into the effect of low and high frequency behaviour, based on the specification of the tower footing resistance (TFR) and measurements of soil resistivity (SR) carried out at selected $500 \mathrm{kV}$ TL towers in Peninsular Malaysia will also be conducted. This will also include the soil profile interpretation study using the CDEGS simulation software.

\section{Methodology}

This section includes a detailed overview of the study method. It discusses in-depth the simulation model built using the SESCAD tool of Current Distribution Electromagnetic Field Grounding and Soil Structure Analysis software (CDEGS) and PSCAD/EMTDC 
software. CDEGS is used to model and interpret the measured data from the field, namely soil structure and earthing system impedance [43]. Since 1978, Safe Engineering Services and Technologies (SES) has been regarded as an undisputed world authority for the effects of soil on the connection between electrical installations and other utilities such as gas and oil pipelines, as well as the communications and railway electrification industries. The CDEGS software is superior and constitutes a powerful collection of integrated engineering software tools designed to model the field measurement (i.e., soil profile and earthing system resistance) and interpret the measured data amongst others. Specifically, two computation modules in CDEGS were used in this study, namely, the RESAP module and the MALT module [43]. This was the primary interface used for data entry, to run calculations and for result analysis. PSCAD/EMTDC is a commercial simulation software that has been used widely in electromagnetic transient modelling and is particularly useful for carrying out this insulation coordination study [44,45]. This work explicitly consists of three types of modelling including soil modelling, earthing modelling and lightning modelling. In particular, the soil profile and earthing design were modelled using CDEGS software in low-frequency steady-state behaviour and the PSCAD/EMTDC software special was used for the lightning behaviour. Figure 2 shows a summary of the simulation work in this study.

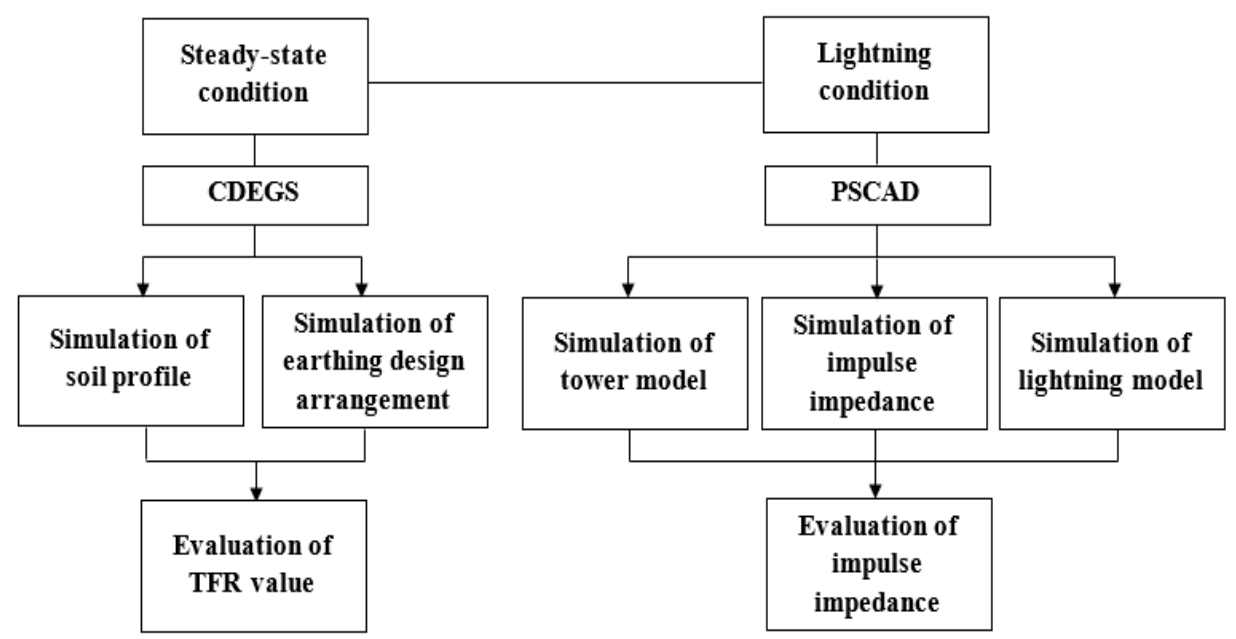

Figure 2. Summary of the simulation work in this study.

\subsection{Description of The Case Study}

A $500 \mathrm{kV}$ double circuit line, known as line A-B (code name used in this study) with a total length of $146.688 \mathrm{~km}$ and 351 towers, was chosen as a case study due to the fact that these $500 \mathrm{kV}$ lines have a high line outage rate and are super-critical to the national grid compared to the $275 \mathrm{kV}$ and $132 \mathrm{kV}$ lines in Malaysia. Further, the A-B line was subsequently selected due to having a high number of interruptions compared to the other $500 \mathrm{kV}$ lines in Malaysia [38,46,47]. In detail, it has been reported that the A-B line had 1.53 outages per $100 \mathrm{~km} /$ year, which is the highest outage rate for $500 \mathrm{kV}$ lines as shown in Table 2 [46].

Table 2. Line performance comparison for $500 \mathrm{kV}$ lines in TNB.

\begin{tabular}{|c|c|c|c|}
\hline Num. & Line Name & Total Number of Outages & Outage Rate Per 100 km/yr \\
\hline 1. & $500 \mathrm{kV} \mathrm{A-B}$ & 21 & 1.53 \\
\hline 2. & $500 \mathrm{kV} \mathrm{A}-\mathrm{C}$ & 2 & 0.52 \\
\hline 3. & 500 kV B-D & 9 & 1.25 \\
\hline 4. & $500 \mathrm{kV} \mathrm{E}-\mathrm{F}$ & 6 & 1.45 \\
\hline
\end{tabular}


This study describes the requirement of a transmission earthing tower to improve the overhead line lightning protection. The basic earthing design for the tower by TNB in Peninsular Malaysia is shown in Figure 3. In this design, the base of the tower is a $15 \mathrm{~m} \times 15 \mathrm{~m}$ square consisting of 1 electrode to be driven at a length of $9 \mathrm{~m}$ into the ground. The burial depth of the electrode is $0.5 \mathrm{~m}$ from the surface of the earth and is constructed from stranded copper with a radius of $6.35 \mathrm{~mm}$ (or $0.00635 \mathrm{~m}$ ) [10]. In the case where the required tower footing resistance could not be achieved with the basic earthing design as shown in Figure 3, a new design is proposed in this study and a detailed design is discussed in the next section. Hence, by the completion of the data collected through the measurement at site, the modelling was developed in the CDEGS and PSCAD/EMTDC software. Three transmission towers were selected and two conditions were considered in the case study i.e., (a) steady-state and (b) lightning condition, as follows:

a. Case study A: Soil profile interpretation

i. $\quad$ Case $\mathrm{A}(1)$ : Soil layer analysis

ii. $\quad$ Case $\mathrm{A}(2)$ : Soil resistivity analysis

b. Case study B: TFR of different earthing designs under steady-state using CDEGS

i. $\quad$ Case $\mathrm{B}(1)$ : Effect of design analysis

ii. $\quad$ Case $B(2)$ : Effect of soil profile analysis

c. Case study C: Impulse impedance under lightning condition using PSCAD/EMTDC

i. $\quad$ Case $\mathrm{C}(1)$ : Effect of soil resistivity under $31 \mathrm{kA}(10 / 350 \mu \mathrm{s})$ peak current

ii. $\quad$ Case C(2): Effect of current amplitude within $10 \mathrm{kA}$ to $200 \mathrm{kA}(10 / 350 \mu \mathrm{s})$ range

iii. Case C(3): Effect of lightning current waveshape of $10 / 350 \mu$ s and $8 / 20 \mu$ s at $31 \mathrm{kA}$ peak current

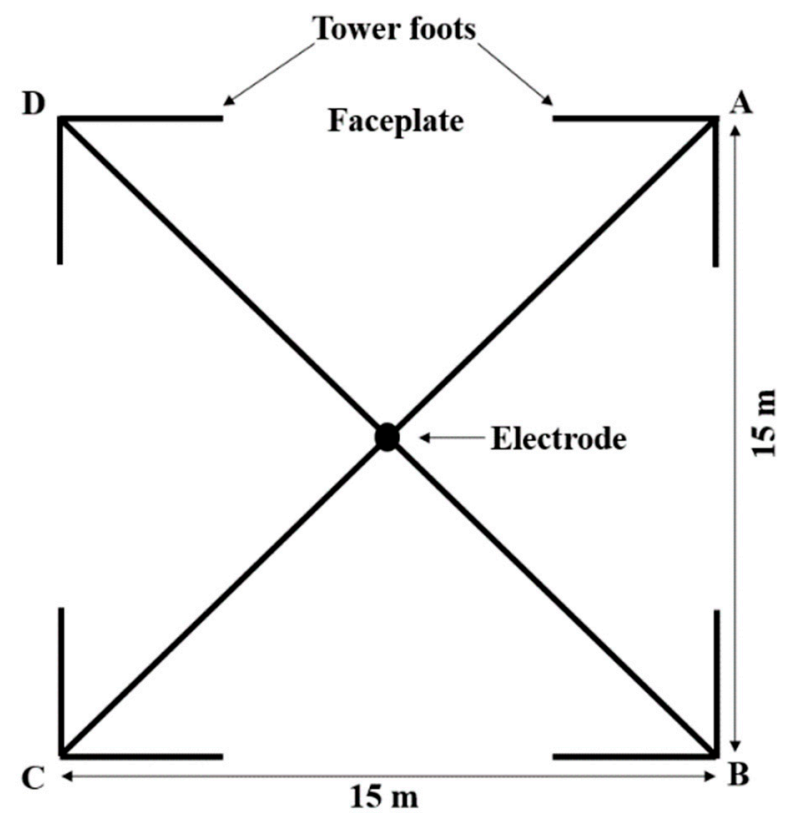

Figure 3. Default earthing design by the utility industry.

\subsection{Steady-State Condition}

This section discusses the modelling of the performance of the low-frequency steadystate condition for the earthing system. The modelling involved under this condition included the soil model and the earthing model using CDEGS software. 


\subsubsection{Soil Model}

Soil modelling is a technique designed to characterise the local soil profile mathematically to construct an earthing system. The soil is usually assumed to be uniform or homogeneous, but in reality, it is often multi-layered. This is due to the geological characteristics that cause the form of the soil to vary from place to place and the presence of rock bottom or groundwater at a depth of the operation resulting in a substantial transformation in resistivity [47-50]. In this study, the RESAP module in CDEGS was used to analyse the soil profile by taking three (3) apparent resistance readings from selected towers. RESAP is dedicated to developing an equivalent soil structure model based on soil resistance measurements. In detail, RESAP is dedicated to designing and interpreting analogous earth profile models based on soil resistivity or apparent resistance data as measured. It can produce models with several horizontal layers and soil models that are both vertically and exponentially layered. The soil resistivity analysis module RESAP was used in this study to classify comparable horizontally layered soils based on the site measurements [43]. Table 3 shows the three values of apparent resistance for Tower T40, Tower T43 and Tower T44. These tests were carried out with various measurements at different locations to achieve the best possible indication of apparent resistance [51-53]. Figure 4 illustrates three measurements at different location areas for every tower. Other than that, a simple apparent resistance data collection during the site measurement was used as input and those data were computed by the Wenner method selected during the simulation as shown in Figure 5 [54,55].

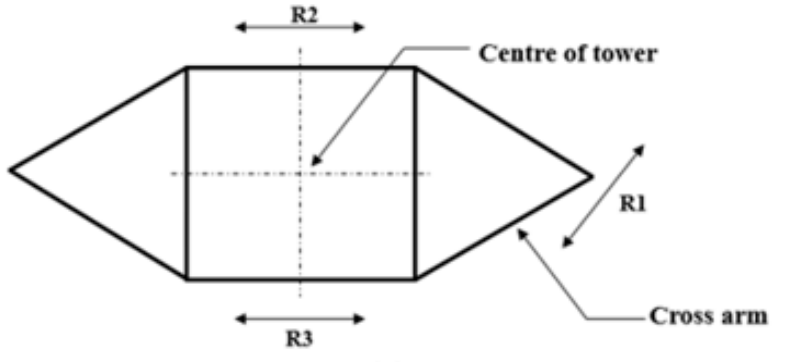

(a)

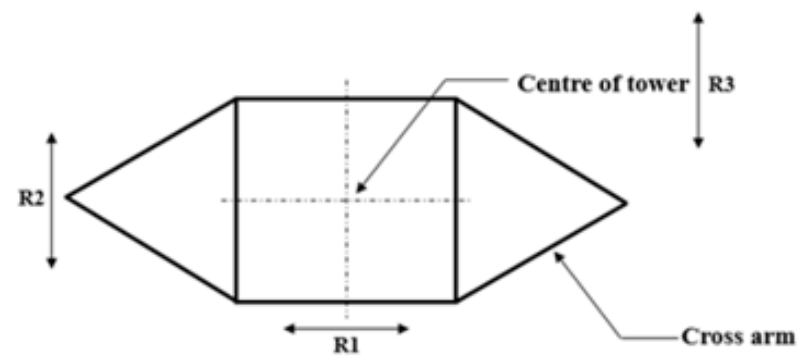

(b)

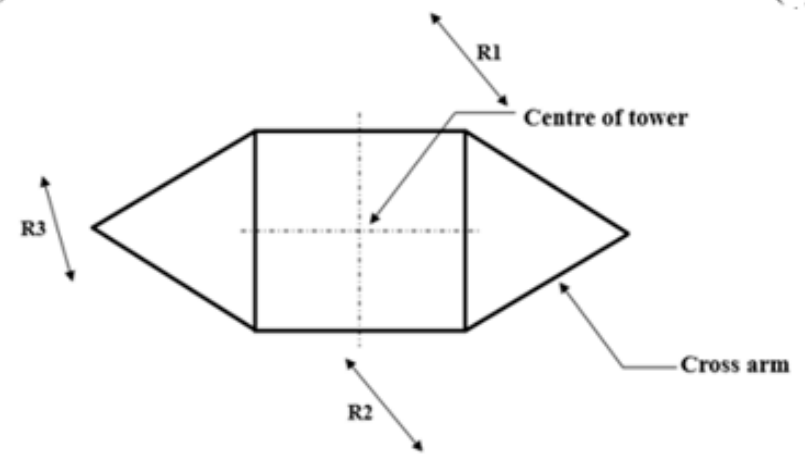

(c)

Figure 4. Top view: Apparent resistance measurements at different location areas (a) Tower T40 (b) Tower T43 (c) Tower T44. 
Table 3. Average of apparent resistance $(\Omega)$ value.

\begin{tabular}{cccc}
\hline \multirow{2}{*}{$\begin{array}{c}\text { Spacing, } \\
(\mathbf{m})\end{array}$} & \multicolumn{3}{c}{ Average Apparent Resistance $(\boldsymbol{\Omega})$} \\
\cline { 2 - 4 } & $\mathbf{T 4 0}$ & $\mathbf{T 4 3}$ & $\mathbf{T 4 4}$ \\
\hline 1 & 28.92 & 256.55 & 232.2 \\
1.5 & 23.18 & 176.15 & 156.67 \\
2 & 17.55 & 144.5 & 109.28 \\
3 & 13.02 & 104 & 56.52 \\
4.5 & 10.21 & 65.69 & 27.75 \\
6 & 6.38 & 48.05 & 18.23 \\
9 & 4.96 & 34.25 & 12 \\
13.5 & 3.92 & 23.6 & 8.98 \\
18 & 2.57 & 19.03 & 4.27 \\
\hline
\end{tabular}

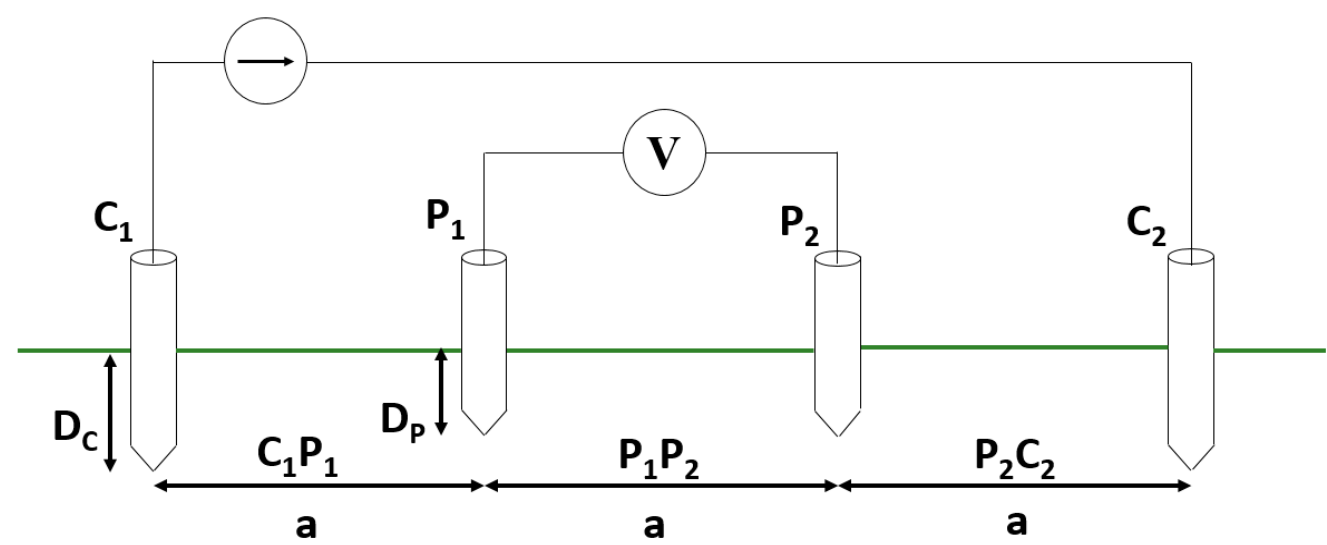

Figure 5. Wenner measurement method.

\subsubsection{Earthing Model}

The effectiveness of the TL efficiency can be greatly improved by a good earthing system design [56]. Typically, the nature of the earthing system design has a relationship to the shape of the tower base. In a high soil resistivity area, a unique earthing design should be applied to the tower base. This section demonstrates the detailed simulation model for the earthing system design. The modelling of the earthing design was developed using SESCAD and implemented by the MALT module to determine the earth resistance. In creating an earthing design model, four (4) main steps in the MALT module solution were presented as shown in Figure 6.

Figure 7 exhibits the additional 'Crowfoot' earthing design adopted and implemented by the electric power utility for which this arrangement was designed by adding vertical, radial and horizontal counterpoises at each tower foot for a continuous length of $20 \mathrm{~m}, 25 \mathrm{~m}$ and $25 \mathrm{~m}$, respectively. Some 16 electrodes were designed with a depth of $3.66 \mathrm{~m}$ (12 feet). All electrodes and counterpoises were set from a type of material made of stranded copper with a radius of $6.35 \mathrm{~mm}$ (or $0.00635 \mathrm{~m}$ ). This design was mandatory as per current practice due to the criticality of this $500 \mathrm{kV}$ transmission line. Therefore, it was in the authors' interest to look at this aspect of the TFR improvement when adopting this particular design. 


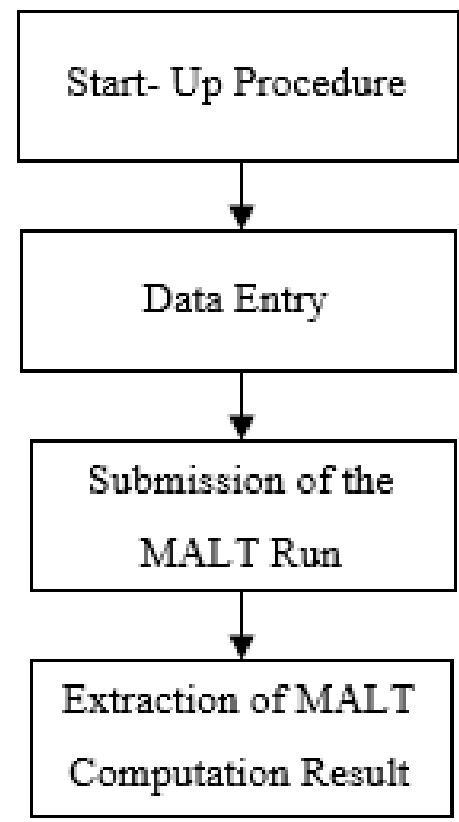

Figure 6. Flow of the earthing design model.

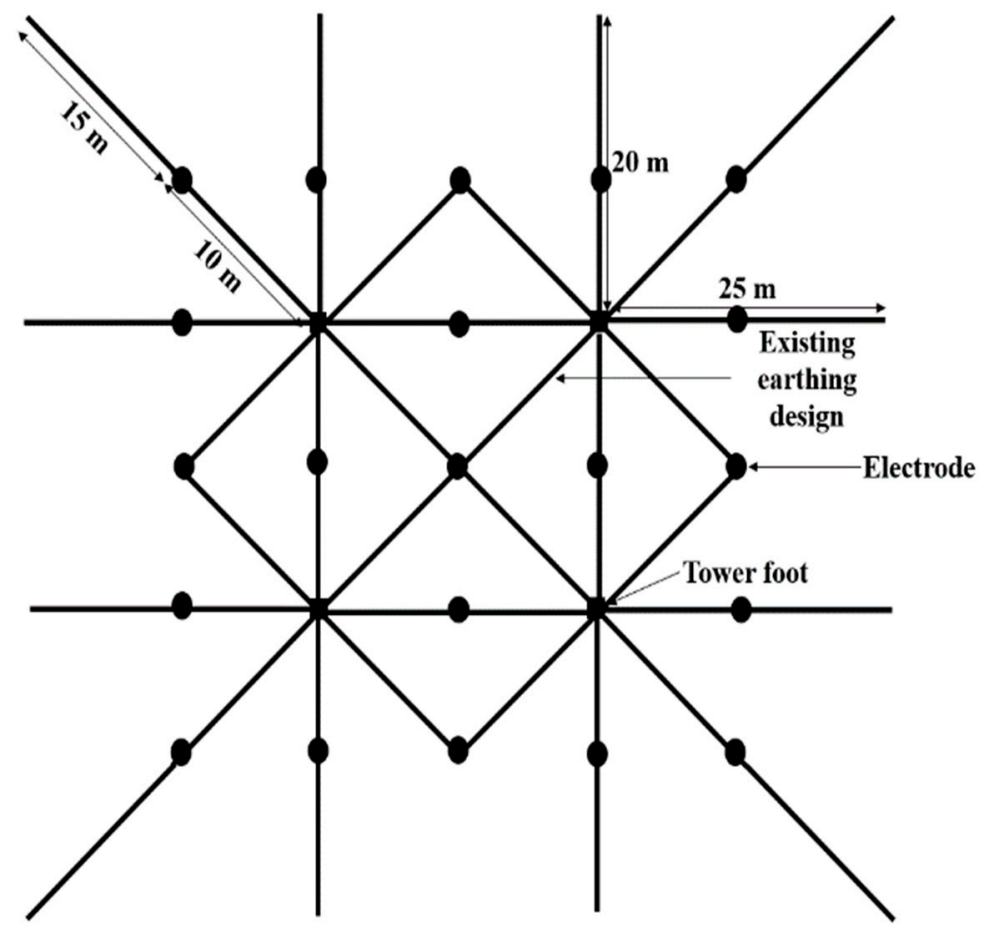

Figure 7. New earthing design: Diamond 'Crowfoot'.

\subsection{Lightning Condition}

The performance of a high-frequency earthing system under lightning conditions is modelled in this section. The modelling includes the tower and lightning current using PSCAD/EMTDC software.

\subsubsection{Tower Model}

The lattice circuit tower of the $500 \mathrm{kV}$ TL is shown in Figure 8a. This tower was developed as a multi-story model based on the representation of the constant parameter circuit. A section between the tower cross arm was modelled in series with a parallel damping resistance and inductance (RL) circuit as a lossless line connected as shown in 
Figure 8b. Subsequently, the Bergeron model in the PSCAD software was chosen in this study to develop the tower modelling for transient simulation in the time domain. The Bergeron model is a technique for determining how a reflection affects an electric signal. This model is the simplest and most accurate of the PSCAD distributed branch models, mainly due to the fact that it is not frequency-dependent $[57,58]$.

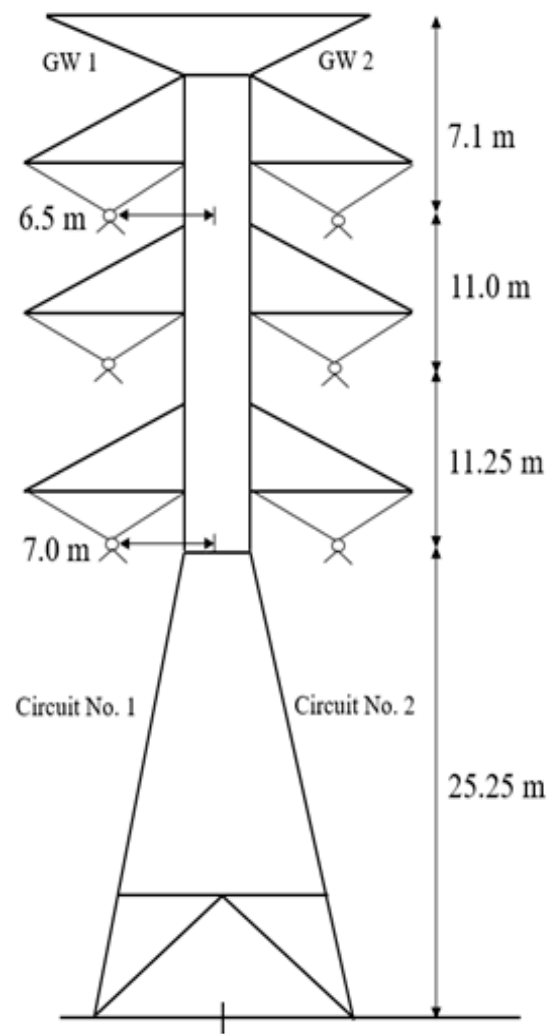

(a)

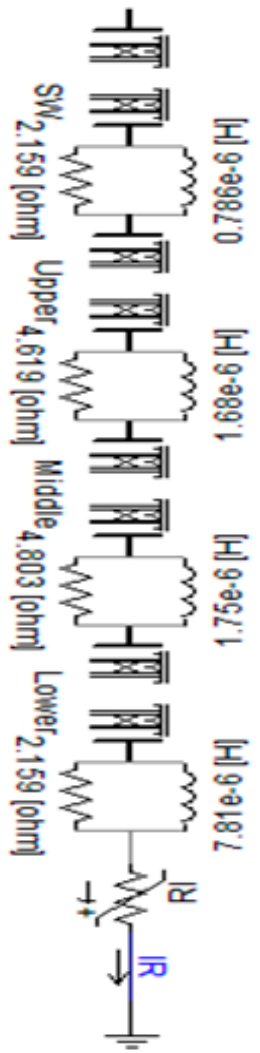

(b)

Figure 8. (a) Structure of the lattice tower for the $500 \mathrm{kV}$ specification (b) Multistorey $500 \mathrm{k}$ transmission tower model with the Bergeron model.

Therefore, the tower surge impedance of each segment was determined employing (2). The parameter of the RL circuit representing the attenuation of the traveling waves was computed based on the equation where $i=1,2,3 \ldots, n, Z_{T 1}$ and $Z_{T 2}$ is the tower surge impedance between each cross arm and cross arm to earth in ohms $(\Omega), h_{t}$ is the total tower height in $\mathrm{m}, h_{1}$ is the height of the top segment in $\mathrm{m}, h_{2}$ is the height of the tower middle segment in $\mathrm{m}, h_{3}$ is the height of the tower bottom segment in $\mathrm{m}, R_{i}$ is the damping resistance in ohms $(\Omega), L_{i}$ is the damping inductance in Henrys $(H), \gamma$ is the attenuation coefficient (in this study it is 0.8 ) and $\alpha$ is a damping coefficient taken as unity. $R_{i}, R_{4}, L_{i}$ and $h$ were calculated using (3) to (6).

$$
\begin{gathered}
Z_{T}=60 \ln \left(\sqrt{2} \sqrt{\left(\frac{h t}{r}\right)^{2}+1}\right) \\
R_{i}=\frac{-2 Z_{T 1} \cdot \ln \sqrt{ } \gamma}{h_{1}+h_{2}+h_{3}} \cdot h_{i}(i=1,2,3) \\
R_{4}=-2 Z_{T 2} \ln \sqrt{ } \gamma \\
L_{i}=\alpha \cdot R_{i} \cdot \frac{2 h}{c}(i=1,2,3,4)
\end{gathered}
$$




$$
h=h_{1}+h_{2}+h_{3}+h_{4}
$$

For multi-story models, the depictions of the tower cross-arms are usually neglected [59]. In this analysis, the travelling wave velocity along the tower was believed to be equal to the speed of light, $c$ at $3 \times 10^{8} \mathrm{~m} / \mathrm{s}$. Table 4 lists the detailed parameter values of the lattice $500 \mathrm{kV}$ tower used to create the tower model.

Table 4. Multi-story circuit parameters of the lattice $500 \mathrm{kV}$ tower model.

\begin{tabular}{ccc}
\hline \multicolumn{1}{c}{ Parameter } & & Value \\
\hline \multirow{3}{*}{ Tower surge impedance } & $Z_{T 1}$ & data \\
& $Z_{T 2}$ & \\
\hline Damping coefficient & $Z_{T 3}$ & 1 \\
\hline Attenuation coefficient & $\alpha$ & 0.8 \\
\hline Speed of light & $\gamma$ & $3 \times 10^{8} \mathrm{~m} / \mathrm{s}$ \\
\hline Tower segment height & $c$ & $7.1 \mathrm{~m}$ \\
& $h_{1}$ & $11.0 \mathrm{~m}$ \\
& $h_{2}$ & $11.25 \mathrm{~m}$ \\
& $h_{3}$ & $25.25 \mathrm{~m}$ \\
\hline Damping resistance & $h_{4}$ & $2.159 \Omega$ \\
& $R_{1}$ & $4.619 \Omega$ \\
& $R_{2}$ & $4.803 \Omega$ \\
& $R_{3}$ & $21.459 \Omega$ \\
\hline Damping inductance & $R_{4}$ & $0.786 \mu \mathrm{H}$ \\
& $L_{1}$ & $1.68 \mu \mathrm{H}$ \\
& $L_{2}$ & $1.75 \mu \mathrm{H}$ \\
& $L_{3}$ & $7.81 \mu \mathrm{H}$ \\
\hline
\end{tabular}

\subsubsection{Lightning Current Model}

A lightning current model is a mathematical framework that replicates certain aspects of the physical process involved in lightning discharge [60]. A special signal transient type of Heidler function as recommended by IEC 62305-1 Ed. 2 [61] was selected in this study. Figure 9 shows the lightning current approximation waveform by the Heidler function, and its equations are expressed in (7) and (8):

$$
f(t)=\frac{I}{\eta} \cdot \frac{\left(t / \tau_{1}\right)^{n}}{1+\left(\frac{t}{\tau^{1}}\right)^{n}} \cdot e^{-t / \tau_{2}}
$$

where

$$
\eta=e^{-t / \tau_{2}} \cdot\left(\frac{n \tau^{2}}{\tau^{1}}\right)^{(1 / n)}
$$




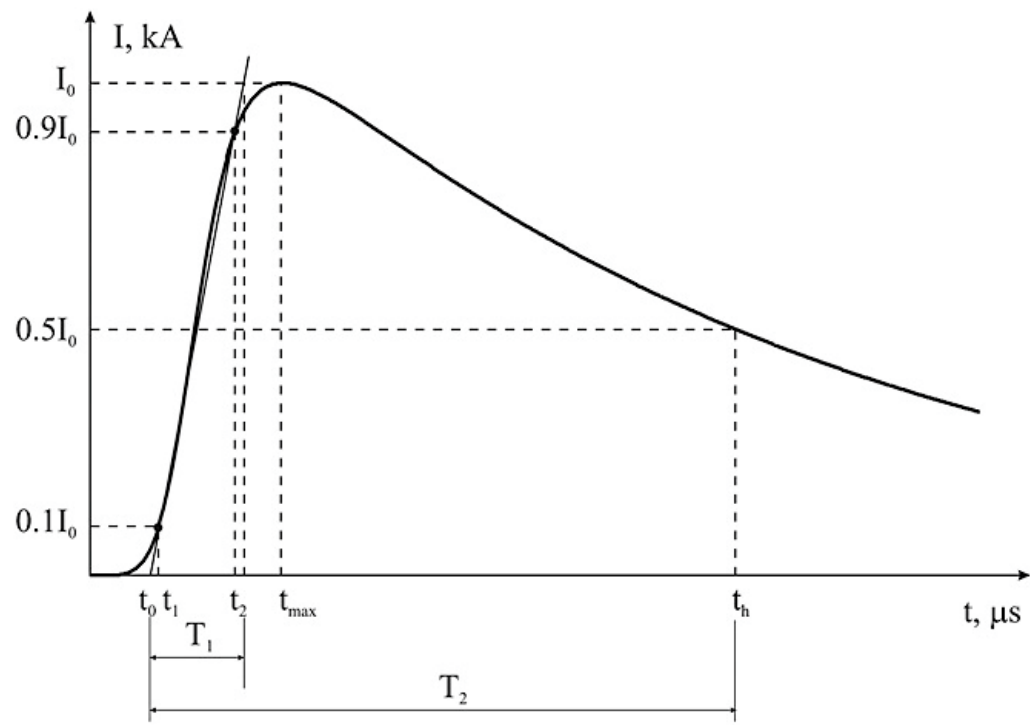

Figure 9. Lightning current approximation by the Heidler function.

There were two waveforms approximated by the Heidler function that represented the conducted lightning current in this study, namely, 8/20 $\mu$ s and 10/350 $\mu$ s. Lightning waveshapes are used to characterise the current waves and the effect for each waveshape. Table 5 represents the Heidler function parameters of the two types of waveshape used by the PSCAD software.

Table 5. Heidler function parameters $[23,24]$.

\begin{tabular}{|c|c|c|c|}
\hline \multicolumn{4}{|c|}{ Heidler Function Parameters } \\
\hline \multicolumn{4}{|c|}{ Current Amplitude, $I_{p}=31 \mathrm{kA}$} \\
\hline \multicolumn{2}{|c|}{$8 / 20 \mu \mathrm{s}$} & \multicolumn{2}{|c|}{$10 / 350 \mu \mathrm{s}$} \\
\hline Parameter & Value & Parameter & Value \\
\hline$\tau_{1}$ & $11.8 \times 10^{-6}$ & $\tau_{1}$ & $3.9 \times 10^{-6}$ \\
\hline$\tau_{2}$ & $8.011 \times 10^{-6}$ & $\tau_{2}$ & $459.65 \times 10^{-6}$ \\
\hline $\mathrm{n}$ & 3 & $\mathrm{n}$ & 2 \\
\hline
\end{tabular}

Within this section of the study, a detailed simulation of the lightning model is presented. Figure 10 represents the lightning model development in PSCAD software. A median (50\%) value of the amplitude current by CIGRE [62] equal to $31 \mathrm{kA}$ was chosen in this study as a constant injected value to investigate the soil resistivity and the lightning waveshape effect. Subsequently, the effect of the amplitude current on the tower earthing system was observed in the range of $10 \mathrm{kA}$ to $200 \mathrm{kA}$ amplitude current by IEEE and CIGRE [62].

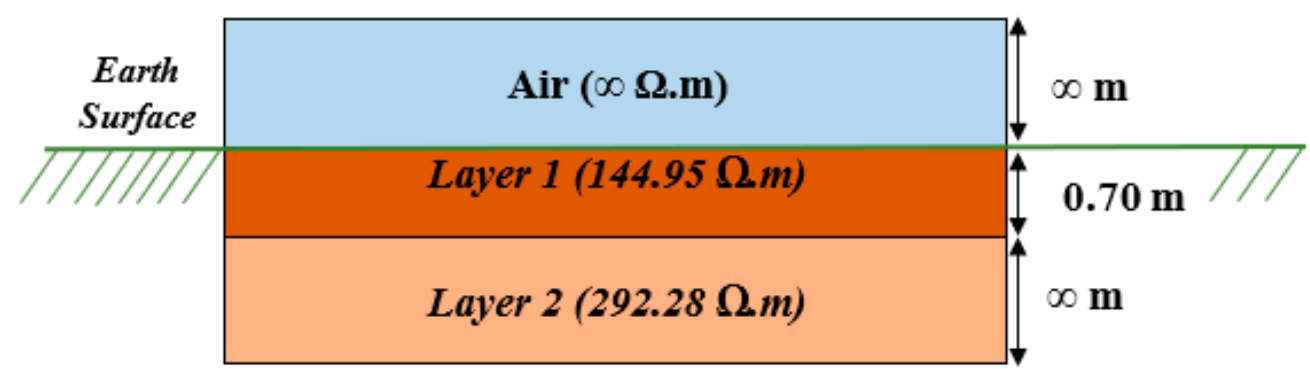

Figure 10. Tower T40 soil profile interpretation. 


\subsubsection{Tower Footing Model}

A significant parameter influencing the occurrence of back-flashover is the tower footing resistance. The tower footing impulse resistance was modelled based on the current dependence model recommended by the IEEE Standard 1313.2-1999 [63] and CIGRÈ [34]. The tower footing model was created by employing (9) and (10) where $R_{o}$ is the tower footing resistance at low current and the frequency measured in ohms $(\Omega), I_{g}$ is the current level needed to initiate sufficient soil ionisation in amperes (A), $I_{R}$ is the lightning current through the footing impedance in Amperes (A), $E_{0}$ is the soil ionisation gradient and $\rho$ is the soil resistivity in Ohm metres $(\Omega \cdot \mathrm{m})$. The value of the soil ionisation gradient is the critical gradient for the breakdown of soil to occur.

$$
\begin{aligned}
R_{i} & =\frac{R_{o}}{\sqrt{1+\frac{I_{R}}{I_{g}}}} \\
I_{g} & =\frac{1}{2 \pi} \frac{E_{o} \rho}{R_{o}{ }^{2}}
\end{aligned}
$$

Note that $R_{o}$ is referred to as TFR in this paper and is also known as low frequency earthing, whilst $R_{i}$ is referred to as tower footing impedance in this paper and is also known as high frequency earthing.

In creating a tower footing impedance model, a Continuous System Model Functions Digital and Analogue Control Blocks (CSMF) was selected in the PSCAD Master Library. This model was created by using square, differencing junction, multiplier, divider, absolute value, square root and an output channel.

\section{Results and Discussion}

\subsection{Computation of Soil Profile Interpretation}

From the modelling simulation, the outcome indicates soil profile variations for each tower. The results show that each tower region consisted of two and four layers with different soil resistivity values and thickness. Figures 10-12 represent the soil profiles for towers T40, T43 and T44 in which towers T40 and T44 had two layers and lastly T43 had four layers. Figure 10 shows that the surface layer for Tower T40 is referred to as air and has an infinite resistivity and thickness. The first layer of soil had $144.95 \Omega \cdot \mathrm{m}$ with a thickness of approximately $0.70 \mathrm{~m}$ and a second layer of $292.28 \Omega \cdot \mathrm{m}$ with infinite thickness. In other words, both layers were considered to have a low soil resistivity for this tower.

Figure 11 shows the soil profile for Tower T43 in which the result indicates that the highest soil resistivity was in the fourth layer at $2036.37 \Omega \cdot \mathrm{m}$ with an infinite thickness. The first, second and third layer were $1563.73 \Omega \cdot \mathrm{m}, 2025.04 \Omega \cdot \mathrm{m}$ and $1859.86 \Omega \cdot \mathrm{m}$, respectively. The thicknesses for each layer was $0.94 \mathrm{~m}, 0.20 \mathrm{~m}$ and $1.37 \mathrm{~m}$, respectively.

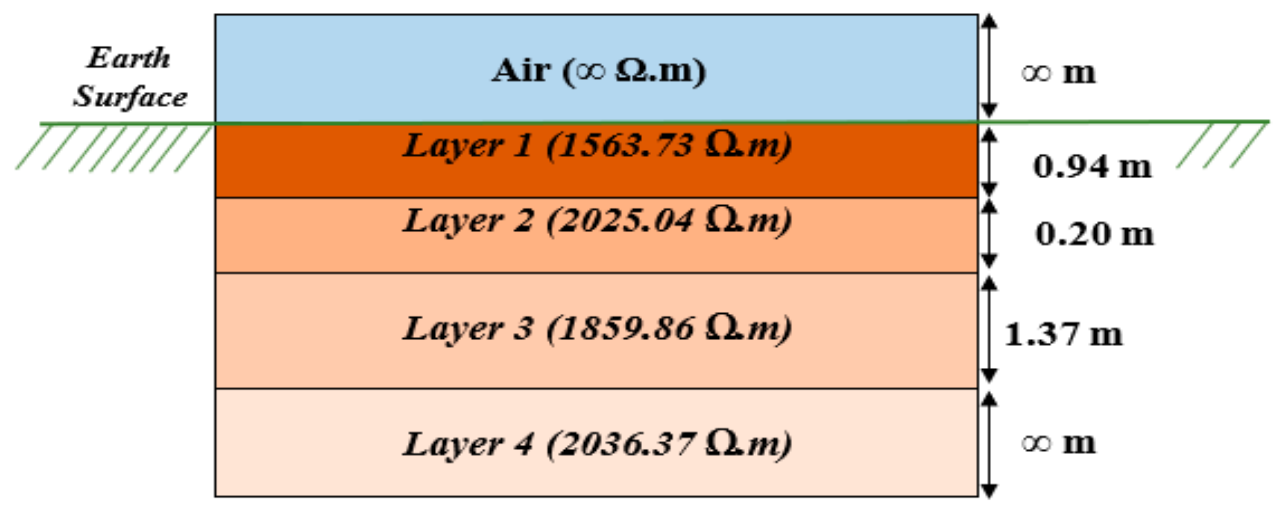

Figure 11. Tower T43 soil profile interpretation. 
The interpretation of the soil profile for Tower T44 in Figure 12 shows that the first layer had a higher soil resistivity than the second layer in which the value of the soil resistivity was $1588.16 \Omega \cdot \mathrm{m}$ with a thickness of approximately $1.92 \mathrm{~m}$, and the soil resistivity for the second layer was $561.46 \Omega \cdot \mathrm{m}$ with an infinite thickness, respectively.

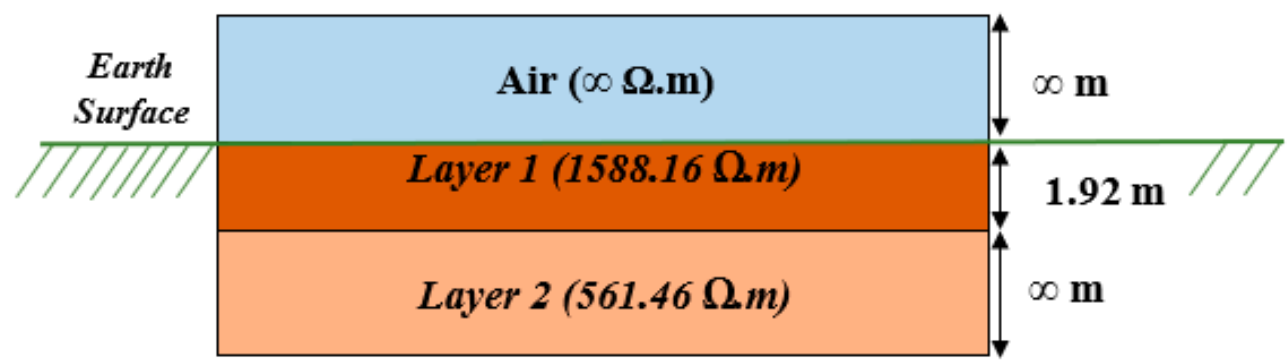

Figure 12. Tower T44 soil profile interpretation.

\subsection{Computation of Tower Footing Resistance (TFR) under Steady-State}

In this section, the tower footing resistance (TFR) computations are presented before and after the earthing system improvement. Specifically, this analysis computed the TFR for the three conditions of the soil profile in Section 3.1. Figure 13 represents the TFR values for the two types of earthing design that were buried in two-layer (Towers T40 and T44) and four-layer (Tower T43) stratified soil. The results indicate that Tower T43 had the highest value of TFR compared to Towers T40 and T44. In this case, the TFR was influenced by the first layer which had a high soil resistivity due to the fact that it had soft topsoil and was porous enough to retain ample air and water. This is in contrast to the middle and bottom layer which were comparatively harder and more compact than the top layer. The lower levels did not contain any organic matter and consisted of rock that made it very rough [64].

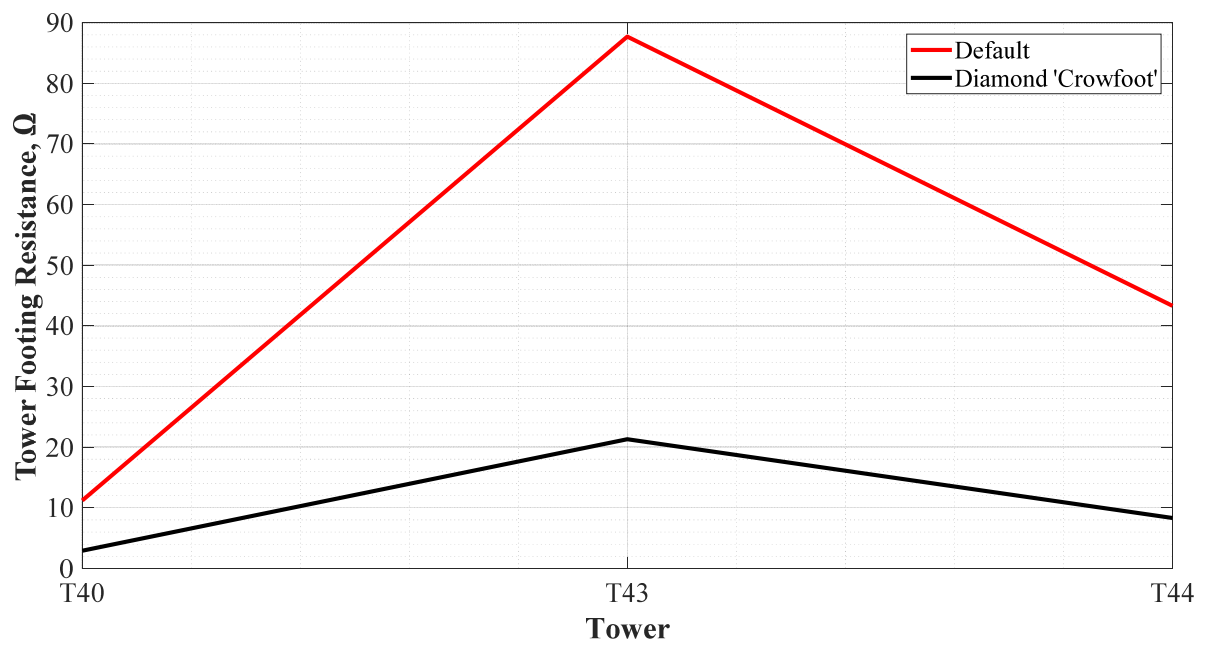

Figure 13. Computed TFR values for towers T40, T43 and T44 based on two earthing designs.

As highlighted earlier in Section 2.2.2, the diamond 'crowfoot' design was proposed as a new design and it is now mandatory that this design is implemented by the electric power utility in order to improve the earthing system performance. The results show improved TFR values at T40, T43 and T44 from $11.2 \Omega, 87.7 \Omega$ and $43.3 \Omega$ to $2.9 \Omega, 21.3 \Omega$ and $8.3 \Omega$, respectively. Interestingly, this demonstrated a reduction of at least $70 \%$ in the tower footing resistance. To be exact, $74.11 \%$ for Tower T40, 75.71\% for Tower T43 and $80.83 \%$ for Tower T44 as shown in Table 6 . Therefore, this is a case that promotes the excellence of the diamond 'crowfoot' design and suggests its use to mitigate the earthing performance of a $500 \mathrm{kV}$ TL. 
Table 6 . The \% reduction in the TFR value before and after improvement.

\begin{tabular}{cccc}
\hline \multirow{2}{*}{$\begin{array}{c}\text { Tower } \\
\text { (SR) }\end{array}$} & \multicolumn{2}{c}{ Tower Footing Resistance (TFR), $\Omega$} & \\
\cline { 2 - 3 } & $\begin{array}{c}\text { Before } \\
\text { (Default) }\end{array}$ & $\begin{array}{c}\text { After } \\
\text { (Diamond ‘Crowfoot') }\end{array}$ & \\
\hline T40 & 11.2 & 2.9 & 74.11 \\
T43 & 87.7 & 21.3 & 75.71 \\
T44 & 43.3 & 8.3 & 80.83 \\
\hline
\end{tabular}

\subsection{Computation of Tower Footing Impedance (TFI) under Lightning Conditions}

In this section, the tower footing impedance computations are presented under lightning conditions for the default and diamond 'crowfoot' designs. This computation was also analysed under three soil resistivity conditions as a steady-state. Three effects, namely (a) soil resistivity, (b) amplitude current and (c) lightning wave shapes were investigated in this study to observe their relationship with the tower footing impedance during the lightning conditions.

\subsubsection{Effect of Soil Resistivity}

Table 7 shows that was a decrease in the tower footing impedance value under lightning behaviour. There was a significant difference between the two situations in which the characteristics of the earthing system were different due to the impact of soil ionisation under lightning conditions. For the default design in this analysis, the results show a decrease of $13 \%$ to $48 \%$ in impedance and for the diamond 'crowfoot' the decrease was just $2 \%$ to $7 \%$. Subsequently, the analysis continued to investigate the effect of soil resistivity during the lightning current injection.

In this section, three types of soil resistivity were chosen with a different range and a current amplitude of $31 \mathrm{kA}(10 / 350 \mu \mathrm{s})$ which was observed to investigate their effect on the earthing system design. Further analysis showed that the tower footing impedance was highly reduced for the high soil resistivity before improving the earthing design. For soil resistivity below $500 \Omega \cdot \mathrm{m}$, the results show just a slight decrease compared to the soil resistivity above $1500 \Omega \cdot \mathrm{m}$ and $500 \Omega \cdot \mathrm{m} \leq \rho<1500 \Omega \cdot \mathrm{m}$. However, the result found no significant reduction for the diamond 'crowfoot' design compared to the default design which consists of more rods and electrodes compared to the default one.

Table 7. Tower footing impedance value for soil resistivity variations before and after improvement.

\begin{tabular}{cccc}
\hline \multirow{2}{*}{ Tower } & Soil Resistivity, & \multicolumn{2}{c}{ Tower Footing Impedance (TFI), $\boldsymbol{\Omega}$} \\
\cline { 3 - 4 } & $\boldsymbol{\Omega} \cdot \mathbf{m}$ & Default & Diamond 'Crowfoot' $^{\text {T40 }}$ \\
\cline { 3 - 4 } T43 & 1840.22 & 9.7 & 2.9 \\
T44 & 743.46 & 45.5 & 19.7 \\
\hline
\end{tabular}

\subsubsection{Effect of Current Amplitude}

The effect of different amplitudes of the lightning current is discussed in this section. The lightning current was injected at the top of the selected towers T40, T43 and T44 ranging from $10 \mathrm{kA}$ to $200 \mathrm{kA}$ and the results are illustrated in Figures 14-16. The results of this analysis indicated that the tower footing impedance was reduced. Interestingly, the tower footing impedance was found to have a high reduction when the lightning current increased. In particular, the findings also indicated that a high soil resistivity had a greater effect on reducing the impedance during the occurrence of a high lightning current. However, no significant reduction was found for the diamond 'crowfoot' design compared to the default design in this analysis. Table 8 presents the results obtained from the simulation analysis of tower footing impedance. 


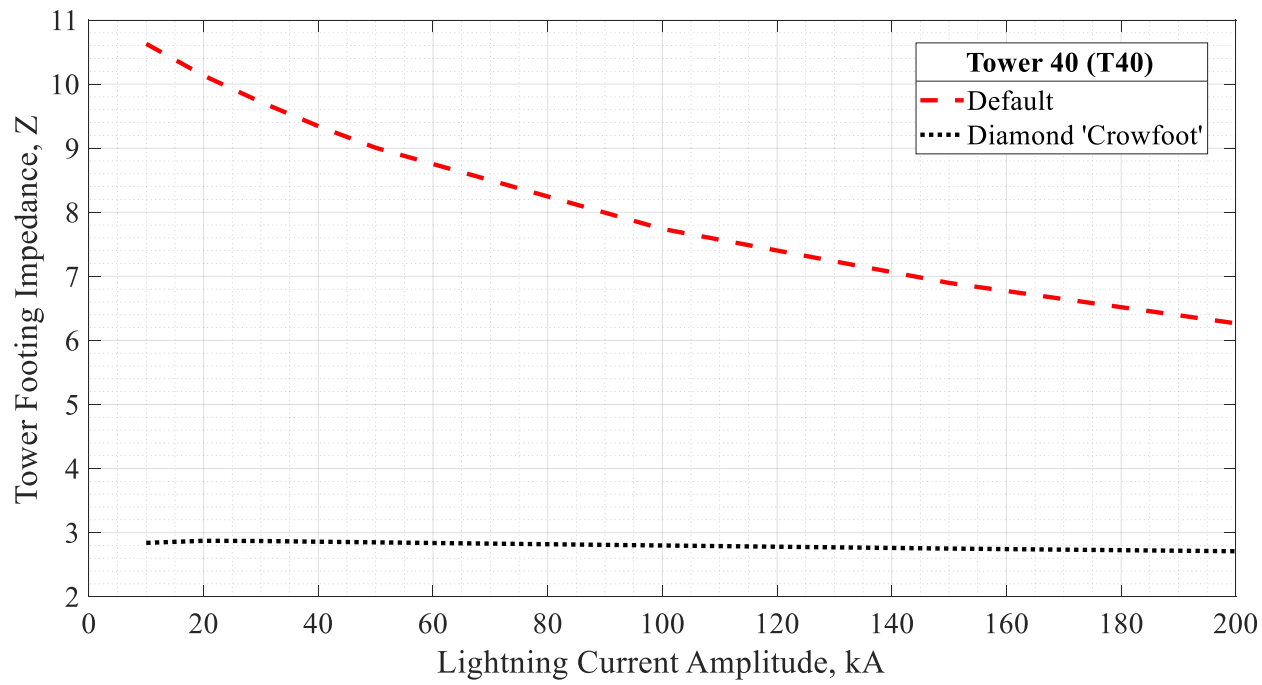

Figure 14. Variation of lightning current amplitude for Tower T40.

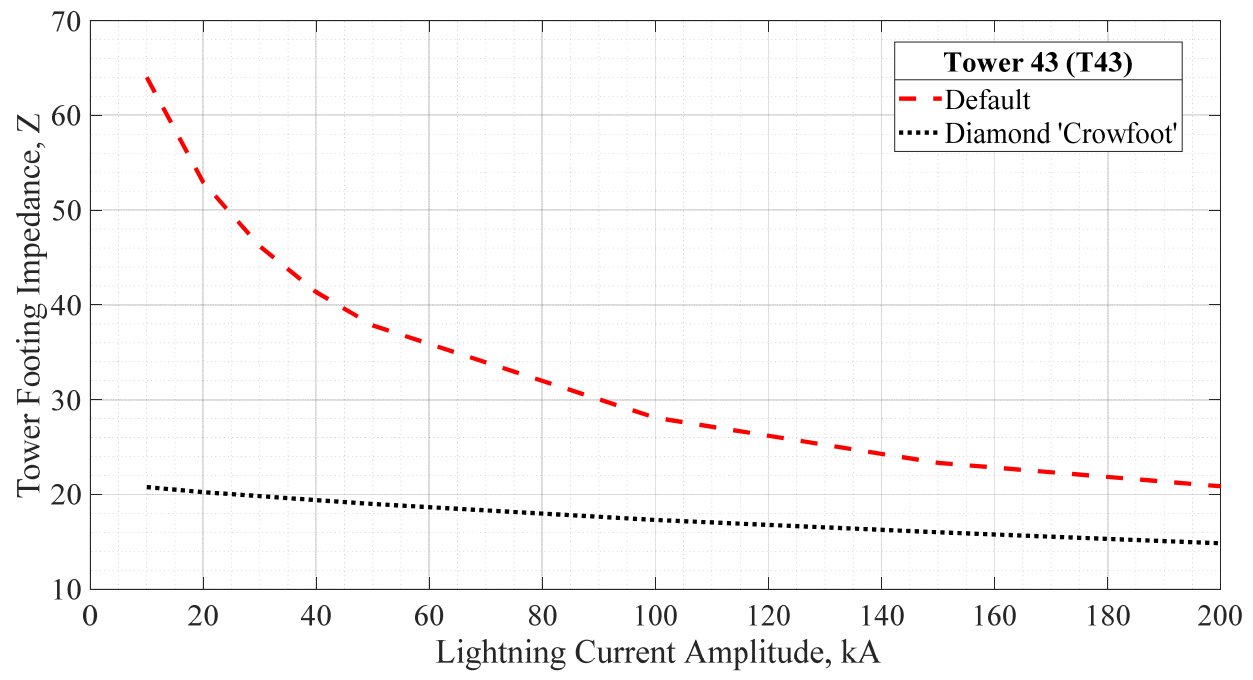

Figure 15. Variation of lightning current amplitude for Tower T43.

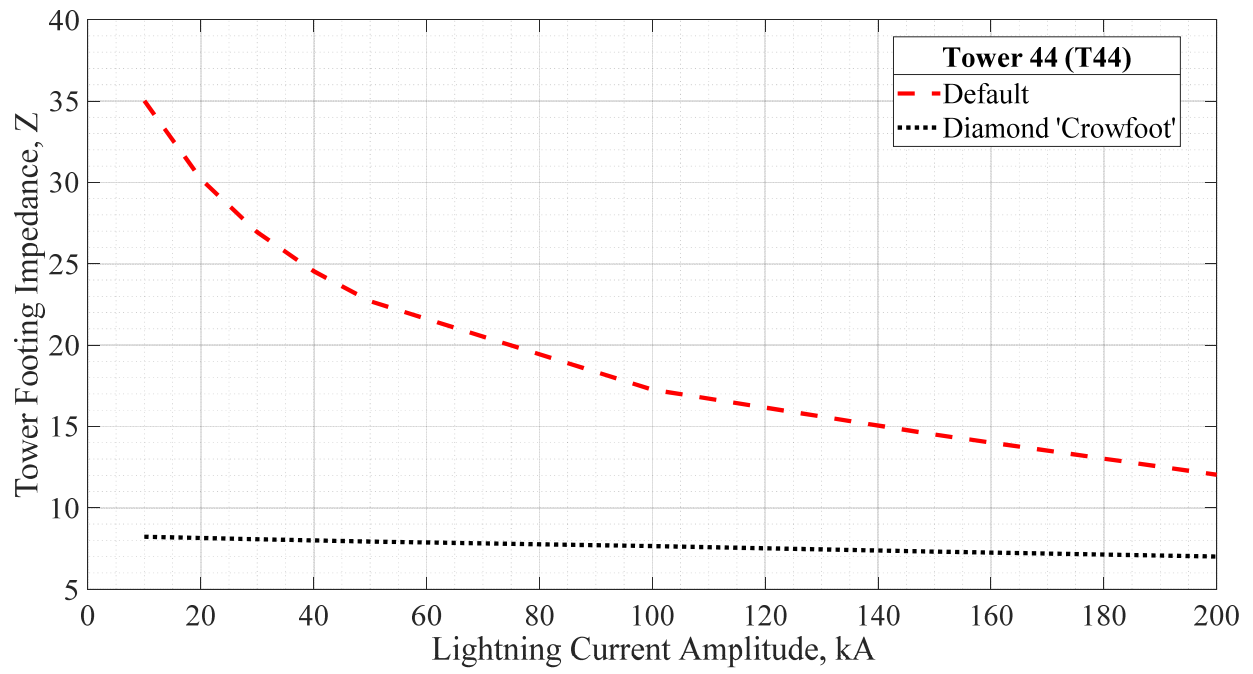

Figure 16. Variation of lightning current amplitude for Tower T44. 
Table 8. Tower footing impedance value for amplitude current variation before and after improvement.

\begin{tabular}{ccccccc}
\hline & \multicolumn{5}{c}{ Tower Footing Impedance, $\Omega$} \\
\cline { 2 - 7 } $\begin{array}{c}\text { Lightning Current } \\
\text { Magnitude, kA }\end{array}$ & \multicolumn{3}{c}{ Default } & \multicolumn{4}{c}{ Diamond 'Crowfoot' } \\
\cline { 2 - 7 } & $\mathbf{T 4 0}$ & $\mathbf{T 4 3}$ & $\mathbf{T 4 4}$ & $\mathbf{T 4 0}$ & T43 & T44 \\
\hline 10 & 10.6 & 64 & 35 & 2.9 & 20.8 & 8.2 \\
20 & 10.1 & 52.9 & 30.2 & 2.9 & 20.2 & 8.1 \\
30 & 9.7 & 46.2 & 26.9 & 2.9 & 19.8 & 8.1 \\
40 & 9.3 & 41.3 & 24.5 & 2.8 & 19.4 & 8 \\
50 & 9 & 37.8 & 22.7 & 2.8 & 19 & 7.9 \\
100 & 7.7 & 28.1 & 17.3 & 2.8 & 17.3 & 7.6 \\
150 & 6.9 & 23.3 & 14.5 & 2.8 & 16 & 7.3 \\
200 & 6.3 & 20.9 & 12 & 2.7 & 14.8 & 7 \\
\hline
\end{tabular}

\subsubsection{Effect of Lightning Waveshapes}

Two variations of lightning current impulse wave shape (a) $8 / 20 \mu \mathrm{s}$ and (b) $10 / 350 \mu \mathrm{s}$ were applied at towers T40, T43 and T44 to investigate their influence on the two earthing systems designs, namely (a) the default design (b) diamond 'crowfoot' with $31 \mathrm{kA}$ by CIGRE [62]. The result was measured as shown in Table 9. This indicated that there was no improvement in tower footing impedance for both lightning current impulse wave shapes. As can be seen from Table 9, the percentage of the reduction was $0.01 \%$ to $0.02 \%$ and no decrease in tower footing impedance was observed for soil resistivity over $1000 \Omega \cdot \mathrm{m}$.

Table 9. Tower footing impedance for lightning waveshape variations before and after improvement.

\begin{tabular}{|c|c|c|c|c|}
\hline \multirow[b]{2}{*}{ Tower } & \multirow[b]{2}{*}{$\begin{array}{l}\text { Soil Resistivity, } \\
\Omega \cdot \mathrm{m}\end{array}$} & \multirow[b]{2}{*}{$\begin{array}{c}\text { Lightning Wave } \\
\text { Shape }\end{array}$} & \multicolumn{2}{|c|}{ Tower Footing Impedance, $\Omega$} \\
\hline & & & Default & $\begin{array}{l}\text { Diamond } \\
\text { 'Crowfoot' }\end{array}$ \\
\hline $\mathrm{T} 40$ & 240.2249 & \multirow{3}{*}{$8 / 20 \mu \mathrm{s}$} & 9.7 & 2.9 \\
\hline $\mathrm{T} 43$ & 1841.0450 & & 45.5 & 19.7 \\
\hline $\mathrm{T} 44$ & 743.4558 & & 26.5 & 8.1 \\
\hline $\mathrm{T} 40$ & 240.2249 & \multirow{3}{*}{$10 / 350 \mu \mathrm{s}$} & 9.6 & 2.8 \\
\hline $\mathrm{T} 43$ & 1841.0450 & & 44.4 & 19.7 \\
\hline $\mathrm{T} 44$ & 743.4558 & & 25.9 & 8 \\
\hline
\end{tabular}

\section{Conclusions}

This paper has provided detail comparative analyses of TFR before and after the improvement of an earthing system design was carried out under steady-state and lightning conditions. This real implementation at site clearly provides information and knowledge sharing on the basis of selection and judgement of the TFR arrangement chosen. The diamond 'crowfoot' new earthing design was proposed in this study, based on its low measurements of TFR to improve the lightning performance for all $500 \mathrm{kV}$ transmission lines in Malaysia. This investigation was modelled and analysed using CDEGS and PSCAD/EMTDC software approaches for steady-state and lightning conditions, respectively. From the results obtained, each tower area in Malaysia was generally found to consist of multiple layers, namely, two layers and four layers. Other than that, the analysis also demonstrated that at least more than $70 \%$ of TFR can be reduced by a diamond 'crowfoot' design. Not only that, when the soil ionisation effect is taken into account, the footing impedance also decreased from $13 \%$ to $48 \%$. During lightning conditions, three effects of tower footing impedance on the earthing system design were determined in this study, namely, (a) soil resistivity, (b) current amplitude and (c) lightning waveshapes. The results indicated that the tower footing impedance may be significantly reduced for high soil resistivity before the earthing design is improved. Nevertheless, no substantial decrease in the diamond 'crowfoot' design was found when the results were compared to the default design possibly because, as expected, the diamond 'crowfoot' design is sufficient enough 
to lower the TFR value. Subsequently, the higher the lightning current amplitude, the lower the tower footing impedance when tested up to $200 \mathrm{kA}$. When comparing the two lightning current waveshapes, no significant difference was found in terms of tower footing impedance values. Overall, it is clear that the study has found that the soil resistivity and earthing design play an important role in the earthing performance for the transmission system.

Author Contributions: Conceptualization, M.Z.A.A.K., M.O., M.S.A.R. and U.A.U.A.; methodology, N.A.F.M.N. and N.H.Z.; validation M.Z.A.A.K.; formal analysis, N.A.F.M.N., M.S.M.N.; investigation, N.A.F.M.N., M.S.M.N., N.H.N.A. and N.H.Z; writing—original draft preparation, N.A.F.M.N.; writing—review and editing, N.A.F.M.N.; supervision M.Z.A.A.K., M.O., M.S.A.R. and U.A.U.A.; project administration, M.Z.A.A.K., M.O., M.S.A.R. and U.A.U.A.; funding acquisition, M.Z.A.A.K., M.O., M.S.A.R. and U.A.U.A., Software, N.H.N.A. and M.S.M.N. All authors have read and agreed to the published version of the manuscript.

Funding: This research was funded by Universiti Tenaga Nasional through UNITEN Bold Grant and URND for RA Scheme. Special thanks to Tenaga Nasional Berhad (Grid Maintenance) team for their kind support on the data.

Institutional Review Board Statement: Not applicable.

Informed Consent Statement: Not applicable.

Data Availability Statement: Not applicable.

Acknowledgments: Not applicable.

Conflicts of Interest: The authors declare no conflict of interest. The funders had no role in the design of the study; in the collection, analyses, or interpretation of data; in the writing of the manuscript, or in the decision to publish the results.

\section{References}

1. Grigsby, L.L. The Electrical Engineering Handbook Series, 2nd ed.; Dorf, R.C., Ed.; IEEE Press: Piscataway, NJ, USA, 2001; ISBN 0849385784.

2. Wang, C.; Liang, X.; Adajar, E.; Loewen, P. Seasonal Variations of Tower Footing Impedance in Various Transmission Line Grounding Systems. In Proceedings of the IEEE Industry Applications Society Annual Meeting, Detroit, MI, USA, 10-16 October 2020.

3. Gupta, B.P. Impulse characteristics of grounding electrodes. J. Inst. Eng. 1981, 64, 178-182.

4. Gonos, I.F.; Stathopulos, I.A. Soil ionisation under lightning impulse voltages. IEE Proc. Sci. Meas. Technol. 2004, 151, $298-304$. [CrossRef]

5. Methods for Measuring the Earth Resistance of Transmission Towers Equipped with Earth Wires; WG. CA. 2.02; CIGRE: Paris, France, 2005.

6. Batista, R.; Caetano, C.E.F.; Paulino, J.O.S.; Boaventura, W.C.; Lopes, I.J.S.; Cardoso, E.N. A study of grounding arrangements composed by vertical electrodes for two-layered stratified soil models. Electr. Power Syst. Res. 2020, 180, 106129. [CrossRef]

7. Tung, C.C.; Lim, S.C. Performance of electrical grounding system in soil at low moisture content condition at various compression levels. J. Eng. Sci. Technol. 2017, 12, 27-47.

8. Illias, H.A.; Su, C.S.; Bakar, A.H.A. Investigation on soil resistivity of two-layer soil structures using finite element analysis method. IET Sci. Meas. Technol. 2021, 15, 120-129. [CrossRef]

9. Permal, N.; Osman, M.; Ariffin, A.M.; Kadir, M.Z.A.A. The impact of substation grounding grid design parameters in nonhomogenous soil to the grid safety threshold parameters. IEEE Access 2021, 9, 37497-37509. [CrossRef]

10. TNB. Supplementary Document TTS-LN-TES (-S-): 500/275/132 kV Monopole and Lattice Tower Earthing Design; Tenaga Nasional Berhad: Kuala Lumpur, Malaysia, 2020.

11. He, J.; Zeng, R.; Zhang, B. Methodology and Technology for Power System Grounding, 1st ed.; John Wiley \& Sons Singapore Pte. Ltd.: Singapore, 2012; ISBN 9781118254950.

12. Arias Velásquez, R.M.; Mejía Lara, J.V. Failures in overhead lines grounding system and a new improve in the IEEE and national standards. Eng. Fail. Anal. 2019, 100, 103-118. [CrossRef]

13. Koehler, F.; Swingler, J. Unconventional flashover mitigation measures to improve the lightning performance of transmission lines. In Proceedings of the IET International Conference on Resilience of Transmission and Distribution Networks (RTDN 2017), Birmingham, UK, 26-28 September 2017.

14. Yasuda, Y.; Hirakawa, Y.; The, N.; Electric, K.; Co, P. Flashover analysis $500 \mathrm{kV}$ transmission grounding resistance. IEEJ Trans. Power Energy 2000, 120, 56-62. [CrossRef] 
15. Wong, C.; Yusop, Z.; Ismail, T. Trend of daily rainfall and temperature in Peninsular Malaysia based on gridded data set. Int. J. Geomate 2018, 14, 65-72. [CrossRef]

16. Kosztaluk, R. Experimental study of transient ground impedances. IEEE Trans. Power Appar. Syst. 1981, PAS-100, 4653-4660. [CrossRef]

17. Moreno, J.; Simon, P.; Faleiro, E.; Asensio, G.; Fernandez, J.A. Estimation of an upper bound to the value of the step potentials in two-layered soils from grounding resistance measurements. Materials 2020, 13, 290. [CrossRef] [PubMed]

18. Ali, A.W.A.; Ahmad, N.N.; Mohamad Nor, N.; Idris, N.F.; Hanaffi, F. Investigations on the performance of grounding device with spike rods (GDSR) with the effects of soil resistivity and configurations. Energies 2020, 13, 3538. [CrossRef]

19. Reffin, M.S.; Ali, A.W.A.; Nor, N.M.; Ahmad, N.N.; Abdullah, S.A.S.; Mahmud, A.; Hanaffi, F. Seasonal influences on the impulse characteristics of grounding systems for tropical countries. Energies 2019, 12, 1334. [CrossRef]

20. Yang, T. Study of reducing ground resistance for transmission tower on rocky mountain tops with constrained area. IEEJE Trans. Electr. Electron. Eng. 2015, 10, 249-255. [CrossRef]

21. Rong, Z.; Shuiming, C.; Siyun, L.; Weihan, W.; Jinliang, H. Impulse characteristics of grounding systems of transmission-line towers in the region with high soil resistivity. In Proceedings of the TENCON '93. IEEE Region 10 International Conference on Computers, Communications and Automation, Beijing, China, 19-21 October 1993; IEEE: Piscataway, NJ, USA, 2002 ; pp. 454-457. [CrossRef]

22. Pavel, S.G.; Maier, V.; Ciorca, C.; Beleiu, H.G.; Birou, I. Optimal design of the vertical earthing with electrodes arranged in line. Appl. Sci. 2020, 10, 1177. [CrossRef]

23. Androvitsaneas, V.P.; Damianaki, K.D.; Christodoulou, C.A.; Gonos, I.F. Effect of soil resistivity measurement on the safe design of grounding systems. Energies 2020, 13, 3170. [CrossRef]

24. Luo, D.; Cao, Y.; Zhang, Y.; Xie, S.; Zhang, C.; Cao, S. Study on structural parameters and analysis method of soil successive impulse discharge channel. Energies 2021, 14, 877. [CrossRef]

25. Moradi, M. Analysis of transient performance of grounding system considering frequency-dependent soil parameters and ionization. IEEE Trans. Electromagn. Compat. 2020, 62, 785-797. [CrossRef]

26. He, J.; Zhang, B. Soil ionization phenomenon around grounding electrode under lightning impulse. In Proceedings of the 2013 Asia-Pacific Symposium on Electromagnetic Compatibility (APEMC), Melbourne, VIC, Australia, 20-23 May 2013; pp. 2-6. [CrossRef]

27. Sekioka, S.; Lorentzou, M.I.; Philippakou, M.P.; Prousalidis, J.M. Current-dependent grounding resistance model based on energy balance of soil ionization. IEEE Trans. Power Deliv. 2006, 21, 194-201. [CrossRef]

28. Gazzana, D.S.; Bretas, A.S.; Dias, G.A.D.; Tello, M.; Thomas, D.W.P.; Christopoulos, C. The transmission line modeling method to represent the soil ionization phenomenon in grounding systems. IEEE Trans. Magn. 2014, 50, 505-508. [CrossRef]

29. Mokhtari, M.; Abdul-malek, Z. The effect of grounding electrode parameters on soil ionization and transient grounding resistance using electromagnetic field approach. Appl. Mech. Mater. 2014, 554, 628-632. [CrossRef]

30. Elzowawi, A.E. Laboratory Characterisation of Soil Ionisation under Impulse Voltages. Ph.D. Thesis, Cardiff University, Cardiff, $\mathrm{UK}, 2016$.

31. Gouda, O.E.; El-Saied, T.; Salem, W.A.A.; Khater, A.M.A. Evaluations of the apparent soil resistivity and the reflection factor effects on the grounding grid performance in three-layer soils. IET Sci. Meas. Technol. 2019, 13, 469-477. [CrossRef]

32. Choi, J.H.; Lee, B.H. An analysis on the Frequency-dependent grounding impedance based on the ground current dissipation of counterpoises in the two-layered soils. J. Electrostat. 2012, 70, 184-191. [CrossRef]

33. Mokhtari, M.; Abdul-Malek, Z.; Gharehpetian, G.B. A critical review on soil ionisation modelling for grounding electrodes. Arch. Electr. Eng. 2016, 65, 449-461. [CrossRef]

34. Guide to Procedures for Estimating the Lightning Performance of Transmission Lines; WG 01, Study Committee 33; CIGRE: Paris, France, 1991; Volume 1.

35. IEEE std 1410. IEEE Guide for Improving the Lightning Performance of Transmission Lines; IEEE-SA Standards Board: New York, NY, USA, 1997.

36. EPRI. Handbook for Improving Overhead Transmission Line Lightning Performance; EPRI: Palo Alto, CA, USA, 2004.

37. Kadir, M.Z.A.A.; Cotton, I. Application of the insulator coordination gap models and effect of line design to backflashover studies. Int. J. Electr. Power Energy Syst. 2010, 32, 443-449. [CrossRef]

38. Rawi, I.; Kadir, M.Z.A.A.; Izadi, M. Seasonal variation of transmission line outages in Peninsular. Pertanika J. Sci. Technol. 2017, 25, 213-220.

39. IEEE std 1410. IEEE Guide for Improving the Lightning Performance of Electric Power Overhead Distribution Lines; IEEE-SA Standard Board: New York, NY, USA, 2004.

40. Rameli, N.; Ab Kadir, M.Z.A.; Izadi, M.; Gomes, C.; Jasni, J. Evaluation of lightning induced voltage due to the effect of design parameters on medium voltage distribution line. J. Teknol. (Sci. Eng.) 2013, 64, 151-155. [CrossRef]

41. Vita, V.; Maris, T.I. Sensitivity analyses of parameters that affect the lightning performance of distribution networks with distributed generation. J. Multidiscip. Eng. Sci. Stud. 2016, 2, 774-781.

42. Power System Technical Performance: Procedures for Estimating the Lightning Performance of Transmission Lines-New Aspects; WG C4. 23; CIGRE Technical Brochure 839; CIGRE: Paris, France, 2020.

43. SES \& Technologies Ltd. A Simple Substation Grounding Grid Analysis; SES: Montreal, QC, Canada, 2017. 
44. Manitoba HVDC Research Centre. A Comprenhensive Resource for EMTDC Users's Guide: Transient Analysis for PSCAD Power System Simulation; Manitoba Hydro International Ltd.: Winnipeg, MB, Canada, 2010.

45. Manitoba HVDC Research Centre. Power Systems Computer Aided Design (PSCAD) User's Guide; Manitoba Hydro International Ltd.: Winnipeg, MB, Canada, 2018.

46. Rawi, I.M. Establishment of Optimal Externally Gapped Line Arrester Specification for $500 \mathrm{kV}$ Transmission Line in Malaysia; Universiti Putra Malaysia: Seri Kembangan, Malaysia, 2017.

47. Reffin, M.S.; Nor, N.M.; Ahmad, N.N.; Abdullah, S. Performance of practical grounding systems under high impulse conditions. Energies 2018, 11, 3187. [CrossRef]

48. Hasan, H.; Hamzehbahmani, H.; Robson, S.; Griffiths, H.; Clark, D.; Haddad, A. Characterization of horizontal earth electrodes: Variable frequency and impulse responses. In Proceedings of the 2015 50th International Universities Power Engineering Conference (UPEC), Stoke on Trent, UK, 1-4 September 2015; pp. 1-5. [CrossRef]

49. Steinsland, V.; Sivertsen, L.H.; Cimpan, E.; Zhang, S. A new approach to include complex grounding system in lightning transient studies and EMI evaluations. Energies 2019, 12, 3142. [CrossRef]

50. Yang, J.; Zou, J. Parameter estimation of a horizontally multilayered soil with a fast evaluation of the apparent resistivity and its derivatives. IEEE Access 2020, 8, 52652-52662. [CrossRef]

51. Southey, R.D.; Siahrang, M.; Fortin, S.; Dawalibi, F.P. Using Fall-of-Potential measurements to improve deep soil resistivity estimates. IEEE Trans. Ind. Appl. 2015, 51, 5023-5029. [CrossRef]

52. Charvin Anoux Group. Understanding Soil Resistivity Testing Effects of Soil Resistivity on Understanding Soil Resistivity Testing; Application Notes; Charvin Anoux Group: Paris, France, 2019.

53. Vasantrao, B.M.; Bhaskarrao, P.J.; Mukund, B.A.; Baburao, G.R.; Narayan, P.S. Comparative study of Wenner and Schlumberger electrical resistivity method for groundwater investigation: A case study from Dhule district (M.S.), India. Appl. Water Sci. 2017, 7, 4321-4340. [CrossRef]

54. Ukar, O.; Zamora, I. Wind farm grounding system design for transient currents. Renew. Energy 2011, 36, 2004-2010. [CrossRef]

55. Ramos-Leanos, O.; Uribe, F.A.; Valcarcel, L.; Hajiaboli, A.; Franiatte, S.; Dawalibi, F.P. Nonlinear electrode arrangements for multilayer soil resistivity measurements. IEEE Trans. Electromagn. Compat. 2020, 62, 2148-2155. [CrossRef]

56. Myint, S.M.; Hla, K.T.; Tun, T.T. Effective earthing system of electrical power engineering department using optimal electrodes. Int. J. Adv. Technol. Eng. Explor. 2020, 7, 28-35. [CrossRef]

57. Texas Instruments. The Bergeron Method: A Graphic Method for Determining Line Reflections in Transient Phenomena; Texas Instruments: Dallas, TX, USA, 1996.

58. Suyaroj, N.; Premrudeepreechacharn, S.; Watson, N.R. Transient state estimation with the Bergeron transmission line model. Turk. J. Electr. Eng. Comput. Sci. 2017, 25, 806-819. [CrossRef]

59. Martinez, J.A. Power System Transients: Parameter Determination, 1st ed.; Taylor \& Francais Group: Boca Raton, FL, USA, 2010; ISBN 9781420065299.

60. Sarajčev, I.; Sarajčev, P.; Vujević, S. Mathematical model of lightning stroke development. In Proceedings of the 2008 16th International Conference on Software, Telecommunications and Computer Networks, Split, Croatia, 25-27 September 2008; pp. 37-41. [CrossRef]

61. IEC 62305-1. Protection against Lightning Part 1: General Principles (IEC 62305-1:2010); IEC: Geneva, Switzerland, 2011.

62. Rakov, V.A.; Borghetti, A.; Bouquegneau, C.; Chisholm, W.A.; Cooray, V.; Cummins, K.; Diendorfer, G.; Heidler, F.; Hussein, A.; Ishii, M.; et al. Lightning Parameters for Engineering Applications; WG C4.407; CIGRE: Paris, France, 2013.

63. IEEE Standard 1313.2. IEEE Guide for the Application of Insulation Coordination; IEEE-SA Standards Board: Piscataway, NJ, USA, 2005.

64. Balasubramanian, A. Characteristics of Soil Profile; University of Mysore: Mysore, India, 2017. 